\title{
Magnitude and Factors Associated with Precervical Cancer among Screened Women in Southern Ethiopia
}

\author{
Terefu Teka (D), Mesfin Kote (iD), Gemechu Kejela, and Tagel Getachew \\ Department of Public Health, College of Medicine and Health Science, Arba Minch University, Arba Minch, Ethiopia \\ Correspondence should be addressed to Terefu Teka; terefuteka8@gmail.com
}

Received 18 October 2018; Revised 23 March 2019; Accepted 22 April 2019; Published 23 May 2019

Academic Editor: Jagdish Khubchandani

Copyright (C) 2019 Terefu Teka et al. This is an open access article distributed under the Creative Commons Attribution License, which permits unrestricted use, distribution, and reproduction in any medium, provided the original work is properly cited.

\begin{abstract}
Background. Cervical cancer is one of the major noncommunicable public health problems among the female population affecting not only the women but also the whole community. Annually, more than half a million new patients are diagnosed with it and over 270,000 deaths occur worldwide. There are very few research efforts conducted on prevalence and associated factors of specific target group in the region. So, this study tries to show the magnitude on all women screened for precervical cancer and serves as a secondary data for other research. Objective. The aim of the study was to assess magnitude of precervical cancer and associated factors among screened women in Arba Minch town and zuria woreda health institutions, southern Ethiopia. Methods. A facility based cross-sectional study was conducted in three health facilities at Arba Minch town and zuria woreda, southern Ethiopia, from June 2015 to June 2017. Data were collected by two nurses that are working in the area of expertise and one health officer as supervisor. Data of 528 screened clients were entered into Epi data version 3.1 using checklist, double data entry verification done and exported to SPSS version 20.0. After cleaning the data, descriptive analysis was done and multivariable logistic regression model was employed to identify predictors of precervical cancer. Finally, statistical significance was declared at $\mathrm{P}<0.05$. Result. In this study, the magnitude of precervical cancer is $27.7 \%$ [95\%CI] (24.1-31.4)]. Having primary educational status (AOR [95\% $\mathrm{CI}])=0.2[0.1,0.96)]$ and secondary educational status $(\mathrm{AOR}[95 \% \mathrm{CI}])=0.1[0.02,0.3])$, having history of smoking $[\mathrm{AOR}(95 \%$ $\mathrm{CI})=3.7$ (1.4-9.9)], having two and more than two life time sexual partners [AOR $(95 \% \mathrm{CI})=2.2(1.1-4.7)$ ], having age at first sexual intercourse less than eighteen years $[$ AOR $(95 \% \mathrm{CI})=6.6(3.14-13.0)]$ were significantly associated with precervical cancer. Conclusion and Recommendation. The magnitude of precervical cancer is $27.7 \%$ as shown in the result of the present study. Level of education, age at first sexual intercourse, history of smoking, and number of sexual partners were predictors of precervical cancer in this study. Thus, any cervical cancer prevention and control effort at the study area should address those predictors pointed out in the present study and should encourage to screen for precervical cancer.
\end{abstract}

\section{Background}

Cancer is a term used for malignant, autonomous, and uncontrolled growth of cells and tissues. It is always named for the part of the body where it starts, even if it spread to other parts of the body later [1]. Cancer of the cervix is a slowly progressive disease starting from cells on the surface of the cervix. These cells are of two types, squamous and columnar cells. Most cervical cancers arise from the squamous cells. It starts with abnormal changes in the cells on the surface of the cervix known as cervical dysplasia. These dysplastic cells are precancerous and gradually progress to cervical cancer [2].
It is caused by a virus called human papilloma virus (HPV), a sexually transmitted infection which has been detected in up to $99 \%$ of women with squamous cervical carcinoma. According to FMOH, almost all-cervical cancers are directly linked to infection with one or more types of human papilloma virus (HPV), one of the most prevalent sexually transmitted infections in the world. Of more than 100 types of HPV that infect the genital tract, 15 to 20 types are linked to cervical cancer. Two of those types-16 and 18-are most often detected in cervical cancer cases $[3,4]$.

Mortality and morbidity due to cancer of the cervix among women remains a global health challenge. Cervical cancer is the second commonest female malignancy next to 
breast cancer in the world and the leading cause of gynecological cancer mortality in developing countries. Annually, more than half a million new patients diagnosed and over 270,000 deaths occur worldwide [5]. In Sub-Saharan Africa, cervical cancer accounts for $22.5 \%$ of all cancer cases in women and eastern Africa is one of the most heavily affected areas with an incidence of more than 30 cases per 100,000 women per year [6].

In Ethiopia, about $33.6 \%$ of women are estimated to harbor cervical HPV infection at a given period of time. From those, 7,095 new cervical cancer cases are diagnosed each year among the general population, making it the second most frequent and top killer cancer among women [7].

In order to tackle the problem, a clinical outreach and facility based screening programs followed by treatment are very effective even in the resource-poor settings. Screening and treating approach or single-visit approach using visual inspection of cervix with acetic acid (VIA) is a very effective prevention strategy for cervical cancer. This strategy had been started in Ethiopia on September 2010 with collaborative effort of Federal Ministry of Health (FMOH) of Ethiopia and path finder international [8]. Furthermore, awareness raising, procuring and distributing logistics, and expansion of cancer treatment service were a strategic plan included in Health Sector Transformation Plan (HSTP). These programs have positive effects on reducing the morbidity and mortality caused by cervical cancer even in resource-poor settings.

Knowing magnitude and factors associated with precervical cancer among screened women helps to take an action in each factor to decrease the morbidity and mortality of cervical cancer and allocate resources at the policy level so as to control the problem and concurrent losses coming with the disease burden. Therefore, the study seeks to assess the magnitude and factors associated with precervical cancer among screened women in Arba Minch town and Arba Minch zuria districts health institutions, Southern Ethiopia. The result of the study will serve as a complementary for the national guideline. Furthermore, findings from this study will provide available information to authorities so that proper measures can be taken according to the results to save the lives of affected women.

\section{Methods}

Facility based cross-sectional study was conducted from July 1 to September 30, 2017, in Arba Minch town and zuria district. All women aged from 30 to 49 years screened for precervical cancer in three health institutions of the town and zuria district were the source population and women screened for precervical cancer aged from 30 to 49 years from June 30, 2015 , to June 30,2017 , in selected health institutions who fulfill the inclusion criteria (aged from 30-49 years, voluntarily go to selected health facilities for precervical cancer screening and screened for precervical cancer) were the study population. Women who were previously or currently diagnosed with cervical cancer and women with incomplete data were excluded from the study.
Sample Size and Sampling Procedure. Sample size was determined by using a single population proportion formula $n=\left(\mathrm{z}(\alpha / 2)^{2} \mathrm{p}(1-\mathrm{p}) / \mathrm{d}^{2}\right)$, by considering the following assumptions: $12.9 \%(\mathrm{P})$ prevalence of precervical cancer among clients screened at Family Guidance Association of Ethiopia [3], 95\% confidence interval, margin of error $3 \%$ and $10 \%$ nonresponse rate. Finally, the sample size becomes 528 .

All health facilities in the study area which provide routine cervical cancer screening and treatment using visual inspection with acetic acid and cryotherapy services were included. Calculated sample size was allocated using probability proportional to size (PPS) and finally simple random sampling was used to select the study subjects.

2.1. Measurements. Cancer is defined as malignant, autonomous, and uncontrolled growth of cells and tissues. Precervical cancer is an abnormal cellular change located around the cervix, which is not progressed to cervical cancer. Cancer screening is a procedure that is performed to identify the presence of abnormal cell in particular tissue. Cervical cancer screening practice: in this study, it is referred to those who ever had got a Papanicolaou/VIA test once in a life time and those who never screened were regarded as having no screening practice. VIA positive (precervical cancer) is when any of the following findings were observed: raised and thickened white plaques of acetowhite epithelium, usually near the SCJ after applying acetic acid 5\%. VIA negative (no precervical cancer) is when any of the following findings were observed: smooth, pink, uniform and featureless; ectropion, polyp, cervicitis, inflammation, nabothian cyst.

2.2. Data Collection Procedure. This study utilized secondary data from women's chart, registration book, client intake form, and client evaluation form. Data was collected from all eligible women's chart using check list, VIA screening registration book, client intake form, standard client evaluation form for cervical cancer prevention and card by two nurses who had comprehensive skills and experience on area of expertise. The data collection process was supervised by one health officer. The check list was prepared in English and pretested on $5 \%$ of the sample size among woman who were screened at other health facilities outside of the study area. Sociodemographic factors, reproductive health, life style, and behavioral characteristics are topics included in the check list.

To assure the quality of data, training was given for data collectors and supervisors for three days before the start of data collection. The checklist was pretested on $5 \%$ of the samples in other health institution before the data collection and pertinent amendment were made on the basis of the findings. The whole check list/standard evaluation format was supervised and reviewed for completeness and consistency before data entry.

2.3. Data Processing and Analysis. After checking its completeness, the collected data was entered using Epi data version 3.1 and exported to statistical package for social science (SPSS) version 20.0 for analysis. Appropriate descriptive analysis was done for sociodemographic variables and prevalence 
of precervical cancer. Binary logistic regression was done and variables with $\mathrm{P}$ value of $<0.25$ at binary logistic regression were interred into multivariable logistic regression. Finally, variables with $\mathrm{P}$ value of $<0.05$ at multivariable logistic regression were considered as significant predictors of the outcome variable.

2.4. Ethical Consideration. Ethical clearance was obtained from Arba Minch University Research Ethic review committee to conduct the study. In addition permission was obtained from Gamo Gofa Zone Health Department, manager of the hospital and head of the health centers. Confidentiality was secured by informing and giving awareness to the data collectors not to record identifiers of the client and disseminate any information obtained from client form and card. In addition, after screened, those women who become positive for precervical cancer were treated with cryotherapy machine, and also information about the cancer was provided for them.

\section{Results}

3.1. Sociodemographic Characteristics. A total of 528 clients aged 30-49 years were screened by (VIA) for precervical cancer from June 2015 to June 2017 at the study health facilities. Among the study participants, 256 (48.5\%) were in the age group of 30-34 years. One hundred forty-eight 148 $(28 \%)$ of the participant were illiterate, while $284(53.8 \%)$, $53(10 \%)$, and $43(8.1 \%)$ attended primary, secondary, and tertiary schools, respectively. Out of the total respondents, $465(88.1 \%)$ were married, 19 (3.6\%) were single, and the rest were widowed, separated, and divorced. More than half 311 (58.9\%) of the respondents were house wives followed by private/NGO employees 91 (17.2\%) (Table 1).

3.2. Reproductive Health Characteristics. Out of the total participants, 489 (92.6\%) used contraceptive methods. Among them, 39 (36.4\%) were using pills, 31.1\% were using injectable, $22.2 \%$ were using implants, and only $3.4 \%$ were using other types of contraceptives. Majority of the study subjects, $346(65.5 \%)$ had regular menstrual history. One hundred forty-one (26.7\%) had history of postcoital bleeding. Among the study subjects, 526 (99.6\%) of them had given birth and from this $451(85.4 \%)$ had parity greater than or equal to two and $75(14.2 \%)$ had parity less than two. Regarding age of the respondents when they gave birth to their first child, 516 $(97.7 \%)$ were greater than or equal to 18 years old (Table 2$)$.

3.3. Lifestyle and Sexual Behavior. Out of the study respondent, $45(8.5 \%)$ of them have history of smoking. Three hundred twenty-seven $(61.9 \%)$ of the respondents started their first sexual intercourse at the age of less than 18 years and the rest started at the age greater than or equal to 18 years. Among the study participants, 189 (35.8\%) had history of STI and $168(32 \%)$ had history of STI in their husband. All of the study participants were tested for HIV, among those 38(7.2\%) were HIV positive and all HIV positive are on ART care. One hundred sixty-four $(31.1 \%)$ of the respondents had two and
TABLE 1: Sociodemographic characteristics of women screened for precervical cancer in Arba Minch town and zuria district, Gamo Gofa zone, SNNPR, Ethiopia, 2017.

\begin{tabular}{lcc}
\hline Variables & Number & Percent $(\%)$ \\
\hline Age & 256 & 48.5 \\
$30-34$ & 147 & 27.8 \\
$35-39$ & 64 & 12.1 \\
$40-44$ & 61 & 11.6 \\
$45-49$ & & \\
Education status & 148 & 28 \\
Illiterate & 284 & 53.8 \\
Primary & 53 & 10 \\
Secondary & 43 & 8.1 \\
Tertiary & & \\
Marital status & 19 & 3.6 \\
Single & 465 & 88.1 \\
Married & 15 & 2.8 \\
Widowed & 14 & 2.7 \\
Divorced & 15 & 2.8 \\
Separated & & \\
Occupation & 311 & 58.9 \\
House wife & 79 & 15 \\
Merchant & 47 & 17.2 \\
Governmental employee & 91 & \\
Private/NGO employee & & \\
\hline
\end{tabular}

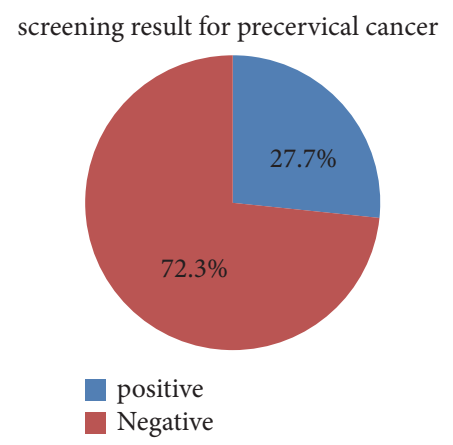

FIgURE 1: Magnitude of precervical screening among screened women in Arba Minch town and zuria district, Gamo Gofa Zone, SNNPR, Ethiopia.

more than two sexual partners in their life and the rest 74 (14\%) had one lifetime sexual partner. Similarly, more than one-fourth of the participants' husbands had two or more than two lifetime sexual partners.

3.4. Magnitude of Precervical Cancer among Screened Women. The proportion of women with precervical cancer in this study was 146 (27.7\%) (Figure 1).

\subsection{Factors Associated with Precervical Cancer}

3.5.1. Binary Logistic Regression. At binary logistic regression analysis, respondents age from 30-34 (COR $[95 \% \mathrm{CI}]=$ 
TABLE 2: Reproductive related characteristics of women screened in Arba Minch town and zuria district, Gamo Gofa Zone, SNNPR, Ethiopia, 2017.

\begin{tabular}{lcc}
\hline Variables & Number & Percent (\%) \\
\hline Contraceptive use & 489 & \\
Yes & 39 & 7.4 \\
No & & \\
Type of contraceptive & 192 & 36.4 \\
Pills & 164 & 31.1 \\
Injectable & 117 & 22.2 \\
Implant & 18 & 3.4 \\
Others & & \\
Menstrual history & 346 & 65.5 \\
Regular & 182 & 34.5 \\
Irregular & & \\
Post coital bleeding & 141 & 26.7 \\
Yes & 387 & 73.3 \\
No & & \\
Give birth & 526 & 99.6 \\
Yes & 2 & 0.4 \\
No & & \\
Number of birth & 451 & 12.4 \\
$\geq 2$ & 75 & \\
$<2$ & 516 & \\
Age at first birth & $12(2.3 \%)$ & \\
$\geq 18$ & & \\
$<18$ & & \\
\hline & & \\
& &
\end{tabular}

$0.4[0.2,0.6])$ and from $35-39(\mathrm{COR}[95 \% \mathrm{CI}]=0.4[0.2,0.8])$, secondary educational level $(\mathrm{COR}[95 \% \mathrm{CI}]=0.1[0.1,0.3])$ and tertiary educational level (COR $[95 \% \mathrm{CI}=0.04[0.2,0.9])$, having history of smoking (COR $[95 \% \mathrm{CI}]=15.7[7.2,35.1])$, less than 18 years age at first intercourse $(\mathrm{COR}[95 \% \mathrm{CI}]=$ $16.1[9.9,26.1])$, women's history of STI $(\mathrm{COR}[95 \% \mathrm{CI}]=$ 11.1[7.1,17.4]), partners history of STIs (COR[95\%CI]= $5.9[3.9,8.9])$, positive HIV sero status (COR[95\%CI]= $5.9[3.9,8.9])$ and having greater than or equal to two sexual partner $(\mathrm{COR}[95 \% \mathrm{CI}]=13.1[7.9,21.5])$ show significant association (Table 3).

3.5.2. Multivariable Logistic Regression. At multivariable logistic regression analysis, women with primary educational status were $80 \%$ less likely to have precervical cancer compared to illiterate women $(\mathrm{AOR}[95 \% \mathrm{CI}])=0.2[0.1,0.96)]$ and women with secondary educational status were $90 \%$ less likely to have precervical cancer compared to illiterate women $(\mathrm{AOR}[95 \% \mathrm{CI}])=0.1[0.02,0.3])$. Women who had history of smoking were almost four times more likely to have precervical cancer compared to those who had no history of smoking $($ AOR $[95 \% \mathrm{CI}])=3.7$ [1.4-9.9]). Similarly, woman who had two or more than two life time sexual partners were 2.2 times more likely to have precervical cancer compared to those who had less than two life time sexual partners $(\mathrm{AOR}[95 \% \mathrm{CI}])=2.2[1.1-4.7])$. In addition, women who had first sexual intercourse at less than eighteen years were 6.6 times more likely to have precervical cancer compared to those who had first intercourse at eighteen or above years $(\mathrm{AOR}[95 \% \mathrm{CI}])=6.6[3.14-13.0])($ Table 4$)$.

\section{Discussion}

In this study, the magnitude of precervical cancer was $27.7 \%$ [95\%CI] (24.1-31.4] and the finding is similar with study conducted in India (27.7\%) [9], but higher than study finding from south west Ethiopia (12.9\%) [5], north Ethiopia Mekele zone (6.7\%) [10], Madagascar (11.3\%) [11], Malawi (12.4\%) [11], and Nigeria (16\% [12]. However, it is lower than study findings from Lusaka Zambia among HIV infected women (76\%) [13]. The higher prevalence in Lusaka Zambia from the present study could be due to the differences in the age of study populations 18 years and older, while this study used $\geq 30$ years. It may also be due to differences in test providers skills and underlying prevalence of other sexually transmitted infections and reproductive characteristics. In addition, it may be partly due to differences in the sexual practices of the women that might increase the prevalence.

This study reveals that having primary and secondary educational status, history of smoking, having two and more than two life time sexual partners of the women, and age at first sexual intercourse were predictors of precervical cancer.

Women with primary educational status were $80 \%$ less likely to have precervical cancer compared to illiterate women and women with secondary educational status were $90 \%$ less likely to have precervical cancer compared to illiterate women. This finding is consistent with study from India and Nepal $[9,14]$. It could be due to increased level of awareness and settings. Lower risk of precervical cancer among literate women and increased level of awareness of precervical cancer among them might have decreased the likelihood of precervical cancer in those women.

Early initiation of intercourse increased the risk of precervical cancer by 6.6 times which is comparable with study from Nigeria [12], India [9], and Brazil [15]. Early onset of sexual activity is thought to be associated with high risk because, during puberty, cervical tissue undergoes physiologic changes, transformation zone on the ecto-cervix is enlarged, and exposure to HPV at such times may facilitate infection which may make this area more vulnerable to development of dysplasia, a cervical squamous precancer. In addition an earlier age of sexual debut implies a longer period of sexual activity a higher likelihood of having many sexual partners and it is inconsistent with study conducted at Addis Ababa [16]. This difference could be due to the differences in the age distribution of study populations, sexual practice or could be due to the sociocultural difference and settings.

Another finding of the present study is that history of multiple sexual partners is also an important predictor of precervical cancer. Woman who had two and more than two life time sexual partners were 2.2 times more likely to have precervical cancer than those who had less than two life time sexual partner. The finding is consistent with previous studies conducted in Southern and Northern Ethiopia and 
TABLE 3: Binary logistic regression analysis showing factors associated with precervical cancer among screened women at Arba Minch town and zuria district, Gamo Gofa zone, SNNPR, Ethiopia, 2017.

\begin{tabular}{|c|c|c|c|c|}
\hline \multirow{2}{*}{ Variables and category } & \multicolumn{2}{|c|}{ VIA result for pre cervical cancer } & \multirow{2}{*}{ COR(95\% CI) } & \multirow{2}{*}{$\mathrm{p}$-value } \\
\hline & Positive & Negative & & \\
\hline \multicolumn{5}{|l|}{ Age } \\
\hline $30-34$ & 59 & 197 & $0.353[0.2,0.6]$ & 0.001 \\
\hline $35-39$ & 38 & 109 & $0.4[0.2,0.8]$ & 0.005 \\
\hline $40-44$ & 21 & 43 & $0.6[0.3,1.2]$ & 0.135 \\
\hline $45-49$ & 28 & 33 & 1 & 1 \\
\hline \multicolumn{5}{|l|}{ Educational status } \\
\hline Illiterate & 64 & 84 & 1 & 1 \\
\hline Primary & 41 & 243 & $0.6[0.3,1.2]$ & 0.148 \\
\hline Secondary & 17 & 36 & $0.1[0.1,0.3]$ & 0.001 \\
\hline Tertiary & 24 & 19 & $0.04[0.2,0.9]$ & 0.021 \\
\hline \multicolumn{5}{|l|}{ Party } \\
\hline$\geq 2$ & 125 & 327 & $1.1[0.6,1.8]$ & 0.851 \\
\hline$<2$ & 20 & 55 & 1 & 1 \\
\hline \multicolumn{5}{|l|}{ History of Smoking } \\
\hline Yes & 37 & 8 & $15.7[7.2,35.1]$ & 0.001 \\
\hline No & 109 & 374 & 1 & 1 \\
\hline \multicolumn{5}{|l|}{ Age at first intercourse } \\
\hline$<18$ & 119 & 82 & $16.1[9.9,26.1]$ & 0.001 \\
\hline$\geq 18$ & 27 & 300 & 1 & 1 \\
\hline \multicolumn{5}{|l|}{ Women history of STI } \\
\hline Yes & 109 & 80 & $11.1[7.1,17.4]$ & 0.001 \\
\hline No & 37 & 302 & 1 & 1 \\
\hline \multicolumn{5}{|l|}{ Partner history of STI } \\
\hline Yes & 89 & 80 & $5.9[3.9,8.9]$ & 0.001 \\
\hline No & 57 & 302 & 1 & 1 \\
\hline \multicolumn{5}{|l|}{ HIV sero status } \\
\hline Positive & 17 & 21 & $2.3[1.2,4.4]$ & 0.001 \\
\hline Negative & 129 & 361 & 1 & 1 \\
\hline \multicolumn{5}{|c|}{ Number of sexual partner of woman } \\
\hline$\geq 2$ & 81 & 83 & $13.1[7.9,21.5]$ & 0.001 \\
\hline$<2$ & 43 & 31 & 1 & 1 \\
\hline
\end{tabular}

Nigeria $[5,10,17]$. Women who had two and more than two lifetime sexual partners develop precervical cancer because as the number of sexual partner increases, they become more prone to acquiring the HPV infection, which is the causative agent for precervical cancer and invasive cervical cancer.

Women who had history of smoking were three times more likely to have precervical cancer than those who did not have history of smoking. Smoking inhibits the immune response to HPV and carcinogenic HPV-infected cells are exposed to smoking carcinogens that cause DNA damage while HPV on coproteins block apoptosis and cell cycle arrest, tobacco-specific polycyclic aromatic hydrocarbons such as benzo [a]pyrene $(\mathrm{BaP})$ and nitrosamines such as 4-(methylnitrosamino)-1-(3-pyridyl)-1-butanone (NNK) which are potent inducers of carcinogenesis have been detected in the cervical mucus of women who smoke and exhibit cervical dysplasia $[18,19]$.

\section{Limitations of the Study}

(i) Since secondary data was used for this study, it was impossible to include some key life style and reproductive characteristics such as family history of precervical cancer, history of abortion, alcohol, and immunosuppressant drug use.

(ii) This study was conducted using cross-sectional study design among women screened for precervical cancer and it does not show cause and effect relationship.

(iii) Women with HIV positive sero status age $>20$ and $<$ 30 year were not included.

(iv) Since the study was conducted only in Arba Minch town and Zuria districts, it cannot be generalized to the whole precervical cancer population of the country. 
TABLE 4: Multivariable logistic regression analysis showing factors associated with precervical cancer among screened women in Arba Minch town and zuria district, Gamo Gofa zone, SNNPR, Ethiopia, 2017.

\begin{tabular}{|c|c|c|c|c|}
\hline \multirow{2}{*}{ Variables and category } & \multicolumn{2}{|c|}{ VIA result for pre cervical cancer } & \multirow{2}{*}{$\operatorname{COR}(95 \% \mathrm{CI})$} & \multirow{2}{*}{$\operatorname{AOR}(95 \% \mathrm{CI})$} \\
\hline & Positive & Negative & & \\
\hline \multicolumn{5}{|l|}{ Age } \\
\hline $30-34$ & 59 & 197 & $0.353[0.2,0.6]$ & $0.5[0.1,2.3]$ \\
\hline $35-39$ & 38 & 109 & $0.4[0.2,0.8]$ & $0.4[0.1,1.1]$ \\
\hline $40-44$ & 21 & 43 & $0.6[0.3,1.2]$ & $0.5[0.2,1.2]$ \\
\hline $45-49$ & 28 & 33 & 1 & 1 \\
\hline \multicolumn{5}{|l|}{ Educational status } \\
\hline Illiterate & 64 & 84 & 1 & 1 \\
\hline Primary & 41 & 243 & $0.6[0.3,1.2]$ & $0.2[0.1,0.96] *$ \\
\hline Secondary & 17 & 36 & $0.1[0.1,0.3]$ & $0.1[0.02,0.3] *$ \\
\hline Tertiary & 24 & 19 & $0.04[0.2,0.9]$ & $0.3[0.1,1.3]$ \\
\hline \multicolumn{5}{|l|}{ Party } \\
\hline$\geq 2$ & 125 & 327 & $1.1[0.6,1.8]$ & $1.46[0.77-2.78]$ \\
\hline$<2$ & 20 & 55 & 1 & 1 \\
\hline \multicolumn{5}{|l|}{ History of Smoking } \\
\hline Yes & 37 & 8 & $15.7[7.2,35.1]$ & $3.7[1.4,9.9] *$ \\
\hline No & 109 & 374 & 1 & 1 \\
\hline \multicolumn{5}{|l|}{ Age at first intercourse } \\
\hline$<18$ & 119 & 82 & $16.1[9.9,26.1]$ & $6.6[3.4-13.0] *$ \\
\hline$\geq 18$ & 27 & 300 & 1 & 1 \\
\hline \multicolumn{5}{|l|}{ Women history of STI } \\
\hline Yes & 109 & 80 & $11.1[7.1,17.4]$ & $1.6[0.7-3.6]$ \\
\hline No & 37 & 302 & 1 & 1 \\
\hline \multicolumn{5}{|l|}{ Partner history of STI } \\
\hline Yes & 89 & 80 & $5.9[3.9,8.9]$ & $1.34[0.41-4.38]$ \\
\hline No & 57 & 302 & 1 & 1 \\
\hline \multicolumn{5}{|l|}{ HIV sero status } \\
\hline Positive & 17 & 21 & $2.3[1.2,4.4]$ & $1.26[0.64-2.50]$ \\
\hline Negative & 129 & 361 & 1 & 1 \\
\hline \multicolumn{5}{|c|}{ Number of sexual partner of woman } \\
\hline$\geq 2$ & 81 & 83 & $13.1[7.9,21.5]$ & $2.2[1.1-4.7] *$ \\
\hline$<2$ & 43 & 31 & 1 & 1 \\
\hline
\end{tabular}

\section{Conclusion}

In this study, the magnitude of precervical cancer was more than a quarter $(27.7 \%)$. Level of education, early initiation of sexual intercourse, smoking, and number of sexual partners were found to be important factors in increasing the risk of precervical cancer.

\section{Recommendations}

Cervical cancer continues to be a public health problem in Ethiopia, but screening using VIA is practical and feasible even in rural settings. With respect to the findings and objectives of the study, some recommendations have been made at different levels. Thus, there is a need to introduce HPV vaccination for girls aged 9-13 years, advocate for the norm of virginity till marriage, avoid Tobacco smoking specifically of Gaya and Kosho, which are predominantly smoked in the area and give health education on smoking, promote delaying of age at initiation of sexual intercourse, give sexuality education tailored to age and culture, and promote and provide condom for those engaged in sexual activity in addressing early initiation of sexual intercourse.

\section{At Federal and Regional Health Offices Level}

(i) There is a need to design strong policy and guidelines on the prevention and control of precervical cancer among women particularly with history of smoking and history of multiple sexual partners.

\section{Health Facilities and Health Professionals}

(i) Health professionals should provide clinical outreach services on precervical cancer to reach more women. 
In addition, they should integrate health education on precervical cancer in the health facilities.

(ii) Health professional should be able to encourage all clients with history of smoking and history of multiple sexual partners to be screened for cervical cancer.

\section{Researchers}

(i) National and local level studies in the wider population need to be conducted to identify and evaluate the risk factors associated with cervical precancerous lesion to find possible interpretation to change them.

(ii) Studies should be done on other related risk factors considering sample size and strong design.

$\begin{array}{ll}\text { Abbreviations } \\ \text { AOR: } & \text { Adjusted Odds Ratio } \\ \text { ART: } & \text { Antiretroviral Therapy } \\ \text { CI: } & \text { Confidence Interval } \\ \text { COR: } & \text { Crude Odds Ratio } \\ \text { FMOH: } & \text { Federal Ministry of Health } \\ \text { HIV: } & \text { Human Immune Virus } \\ \text { HPV: } & \text { Human Papilloma Virus } \\ \text { HSTP: } & \text { Health Sector Transformation Plan } \\ \text { PPS: } & \text { Probability to Population Size } \\ \text { SNNPR: } & \text { Southern Nation Nationalities and Peoples } \\ & \text { Region } \\ \text { SPSS: } & \text { Statistical Package for Social Science } \\ \text { STI: } & \text { Sexually Transmitted Infections } \\ \text { VIA: } & \text { Visual Inspection with Acetic acid. }\end{array}$

\section{Data Availability}

The data used to support the findings of this study are available from the corresponding author upon request.

\section{Ethical Approval}

Ethical clearance was obtained from Arba Minch University Research Ethic Review Committee to conduct the study. In addition permission was obtained from Gamo Gofa Zone Health Department, manager of the hospital, and head of the health centers. Confidentiality was secured by informing and giving awareness to the data collectors not to record identifiers of the client and disseminate any information obtained from client form and card.

\section{Conflicts of Interest}

The authors declare that they have no conflicts of interest regarding the publication of the paper.

\section{Authors' Contributions}

All authors wrote the proposal, participated in data collection, analyzed the data and drafted the paper, approved the proposal with great revisions, and revised subsequent drafts of the paper. In addition, all authors contributed in the design of the methodology and write-up and they read and approved the final manuscript.

\section{Acknowledgments}

Authors would like to thank Arba Minch University, College of Medicine and Health Sciences for initiating them to conduct this study and for financial support. Deep appreciations have gone to managers of hospital and health centers. Also, special thanks are due to data collectors, supervisors, and all people who were involved in the study directly or indirectly. The study was funded by Arba Minch University.

\section{References}

[1] "U.S. Department of Health and Human Services Centers for Disease Control and Prevention. Inside knowledge cervical cancer. Get the Facts About Gynecologic Cancer," 2012, http://www.cdc.gov/cancer/knowledge.

[2] J. S. Berek, Berek and Novak's Gynaecology, Lippincott Williams \& Wilkins, Stanford, Calif, USA, 14th edition, 2007.

[3] D. Zewdie, T. Fessahaye, and F. Henok, "Prevalence and factors associated with VIA positive result among clients screened at family guidance association of Ethiopia, south west area office, Jimma model clinic," BMC Research Notes, vol. 8, article 618, 2015.

[4] X. Castellsague, S. De Sanjose, T. Aguado et al., HPV and Cervical Cancer in the World, vol. 25, Elsevier Ltd., 2007.

[5] A. Gedefaw, A. Astatkie, and G. A. Tessema, "The prevalence of precancerous cervical cancer lesion among HIV-infected women in Southern Ethiopia: a cross-sectional study," PLoS ONE, vol. 8, no. 12, Article ID e84519, 2013.

[6] J. D. Makuza, S. Nsanzimana, M. A. Muhimpundu, L. E. Pace, J. Ntaganira, and D. J. Riedel, "Prevalence and risk factors for cervical cancer and pre-cancerous lesions in Rwanda," Pan African Medical Journal, vol. 22, 2015.

[7] "Human papilloma virus and related casancers, summary report update," 2010.

[8] "International. P. Single-Visit Approach to Cervical Cancer Prevention. Clinical Standards of Practice and Counseling Guidelines," May 2012.

[9] F. Roopali, G. Shashi, and G. Subash, "Sociodemographic risk factors for cervical cancer in Jammu region of J and k state of India," Indian Journal of Scientific Research, vol. 9, pp. 105-110, 2014.

[10] H. Bayu, Y. Berhe, A. Mulat, and A. Alemu, "Cervical cancer screening service uptake and associated factors among age eligible women in Mekelle Zone, Northern Ethiopia, 2015: a community based study using health belief model," PLoS ONE, vol. 11, no. 3, p. e0149908, 2016.

[11] WHO, Prevention of Cervical Cancer through Screening Using Visual Inspection with Acetic Acid (VIA) And Treatment with Cryotherapy. A Demonstration Project in Six African Countries: (Malawi, Madagascar, Nigeria,Uganda, The United Republic of Tanzania, And Zambia), WHO, Geneva, Switzerland, 2012.

[12] B. Utoo, P. Utoo, S. Ngwan, S. Anzaku, and M. Daniel, “Cervical intraepithelial neoplasia: prevalence, risk factors, and utilization of screening services among an urban population in Nigeria," 
Tropical Journal of Obstetrics and Gynaecology, vol. 33, no. 3, pp. 279-283, 2016.

[13] V. V. Sahasrabuddhe, M. H. Mwanahamuntu, S. H. Vermund et al., "Prevalence and distribution of HPV genotypes among HIV-infected women in Zambia," British Journal of Cancer, vol. 96, no. 9, pp. 1480-1483, 2007.

[14] D. Gyenwali, J. Pariyar, and S. R. Onta, "Factors associated with late diagnosis of cervical cancer in Nepal," Asian Pacific Journal of Cancer Prevention, vol. 14, no. 7, pp. 4373-4377, 2013.

[15] S. Ferreira, A. Ferreirade, and Koifman S., "Genetic polymorphisms and environmental risk factors associated with cervical carcinogenesis in a cohort of Brazilian women with cervical lesions," Toxicol Environtal Health, vol. 73, no. 13-14, pp. 888900, 2010.

[16] H. Teame, A. Addissie, W. Ayele et al., "Factors associated with cervical precancerous lesions among women screened for cervical cancer in Addis Ababa, Ethiopia: A case control study," PLoS ONE, vol. 13, no. 1, p. e0191506, 2018.

[17] O. Uzoma, A. Maryam, M. Fatima et al., "Cervical cancer risk factors among HIV-infected Nigerian women," BMC Public Health, vol. 13, article 582, 2013.

[18] P. E. Castle, C. Meyers, S. Alam, and M. J. Conway, "How does tobacco smoke contribute to cervical carcinogenesis?" Journal of Virology, vol. 82, no. 12, pp. 6084-6086, 2008.

[19] A. Samina and C. Horng, "The cigarette smoke carcinogen benzo pyrene enhances human papillomavirus," Synthesis, vol. 82, no. 2, article 1053, 2008. 


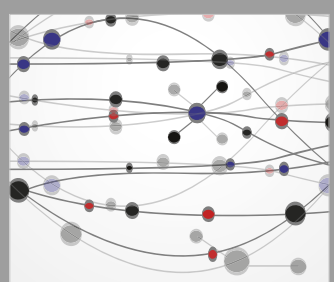

The Scientific World Journal
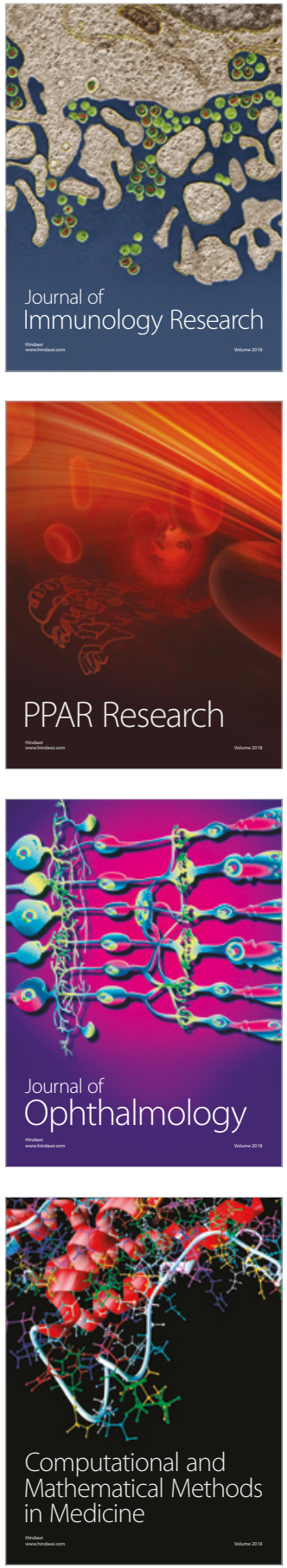

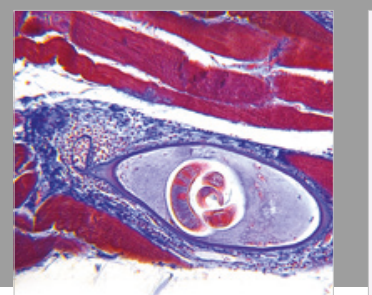

Gastroenterology Research and Practice

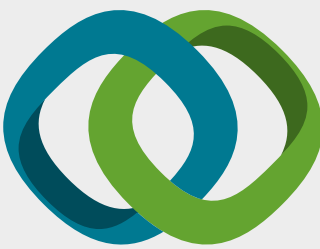

\section{Hindawi}

Submit your manuscripts at

www.hindawi.com
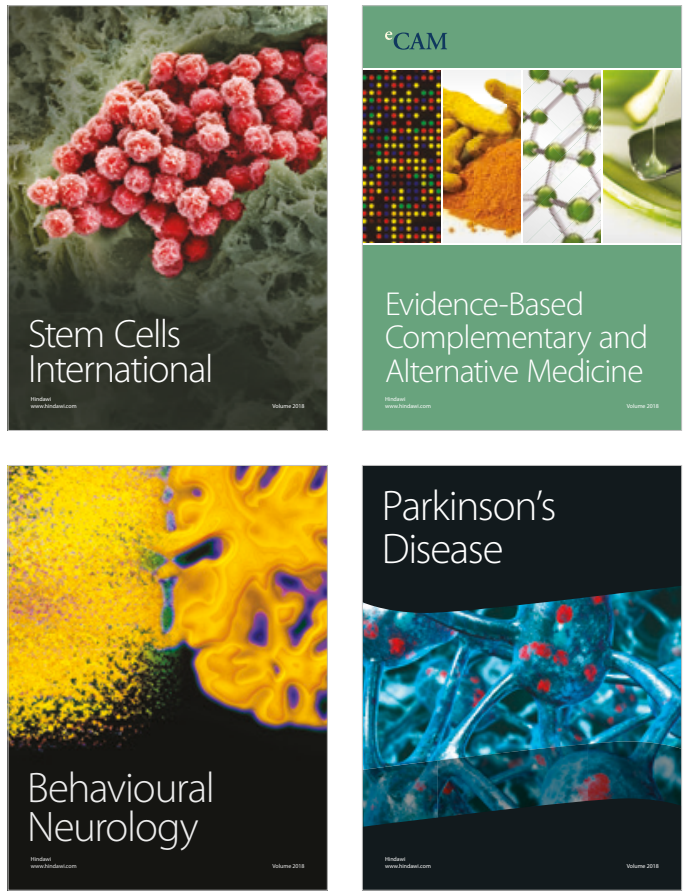

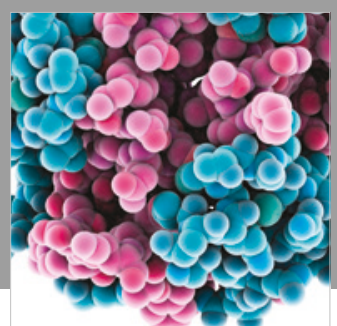

ournal of

Diabetes Research

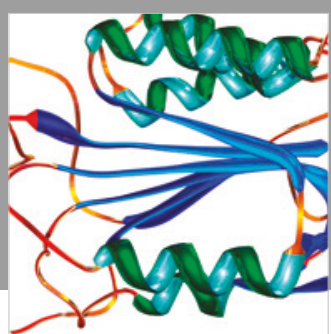

Disease Markers
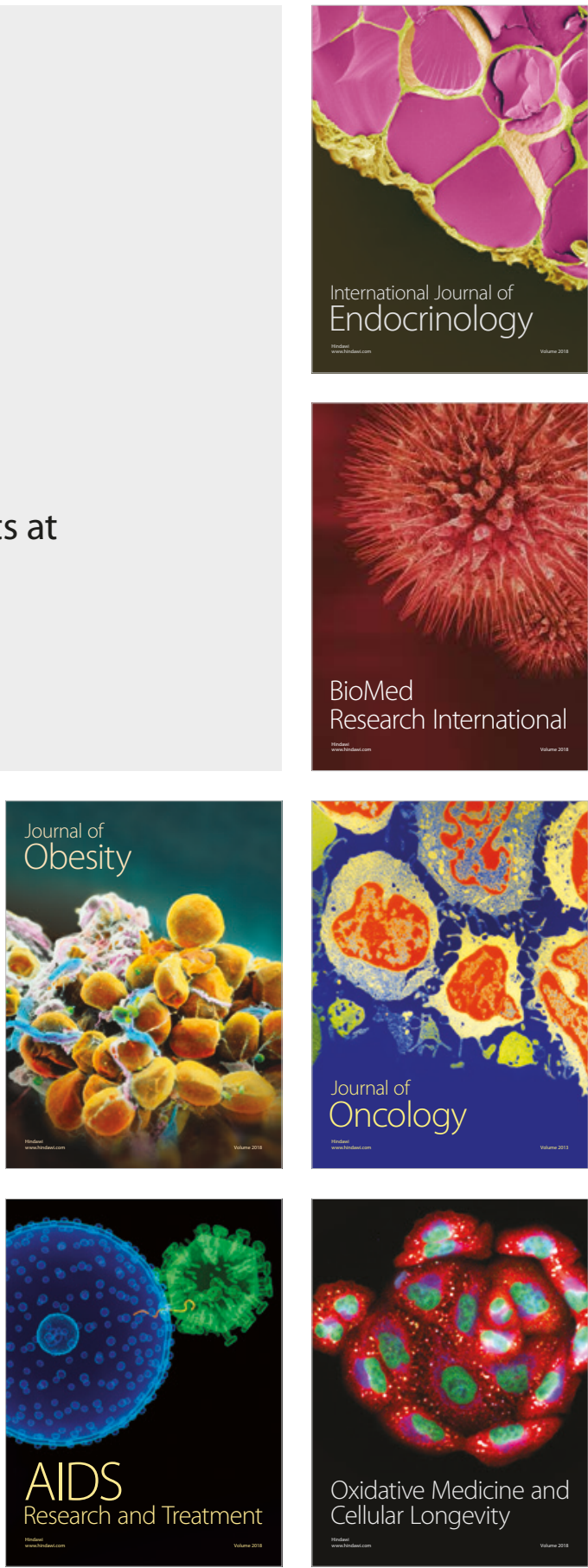